\title{
Prediction of the mechanical behaviour of the Oporto granite using Data Mining Techniques
}

\author{
Francisco F. Martins ${ }^{a}$, Arlindo Begonha ${ }^{\text {b }}$, M. Amália Sequeira Braga
}

\begin{abstract}
The determination of mechanical properties of granitic rocks has a great importance to solve many engineering problems. Tunnelling, mining and excavations are some examples of these problems. The purpose of this paper is to apply Data Mining (DM) techniques such as multiple regressions (MR), artificial neural networks (ANN) and support vector machines (SVM), to predict the uniaxial compressive strength and the deformation modulus of the Oporto granite. This rock is a light grey, two-mica, medium-grained, hypidiomorphic granite and is located in Oporto (Portugal) and surrounding areas. Begonha (1997) and Begonha et al. (2002) studied this granite in terms of chemical, mineralogical, physical and mechanical properties. Among other things, like the weathering features, those authors applied correlation analysis to investigate the relationships between two properties either physical or mechanical or physical and mechanical. This study took the data published by those authors to build a database containing 55 rock sample records. Each record contains the free porosity $\left(\mathrm{N}_{48}\right)$, the dry bulk density (d), the ultrasonic velocity $(\mathrm{v})$, the uniaxial compressive strength $\left(\sigma_{\mathrm{c}}\right)$ and the modulus of elasticity $(\mathrm{E})$. It was concluded that all the models obtained from DM techniques have good performances. Nevertheless, the best forecasting capacity was obtained with the SVM model with $\mathrm{N}_{48}$ and $\mathrm{v}$ as input parameters.
\end{abstract}

Keywords - granite, weathering, mechanical properties, DM techniques, artificial neural networks, support vector machines

${ }^{a}$ Associate Professor, Department of Civil Engineering/Territory Environment and Construction Centre, School of Engineering, University of Minho, Campus de Azurém 4800-058 Guimarães, Portugal. E-mail: ffm@ civil.uminho.pt. Tel.: +351 253510 202. Fax : +351 253510 217. (Corresponding author)

b Assistant Professor, Faculty of Engineering, Department of Civil Engineering, University of Oporto, Rua Dr. Roberto Frias, s/n, 4200-465 Porto, Portugal. E-mail: abegonha@fe.up.pt.

${ }^{\mathbf{c}}$ Associate Professor, Department of Earth Sciences/Centre of Geological Research, Management and Valorisation of Resources, School of Sciences, University of Minho, Campus de Gualtar, 4710-057 Braga, Portugal. E-mail: masbraga@dct.uminho.pt.

\section{Introduction}

Uniaxial compressive strength and modulus of elasticity are very important parameters in the analyses of rock masses behaviour. These parameters are used to study underground and surface mining, slope stability, drilling and blasting and mechanical rock engineering (Tiryaki, 2008). Furthermore, they assume great importance in analytical and numerical solutions.

To take into account the many factors that affect the strength and deformability of rock masses, large scale in situ tests should be performed. Because such tests are very expensive and consume a lot of time, the unconfined compressive lab tests are an alternative to them. However, even the latter tests require a heavy frame and a careful preparation of the rock cores and continue to be more expensive and time consuming than other tests based on index properties. These easier and faster tests have been performed to obtain index properties that can be correlated both with uniaxial compressive strength $\left(\sigma_{\mathrm{c}}\right)$ and modulus of elasticity $(\mathrm{E})$.

Irfan and Dearman (1978) presented correlations for granites between the uniaxial compressive strength and density, the effective porosity and the uniaxial compressive strength, the Young's modulus and effective porosity and the Young's modulus and sonic velocity. Christaras et al. (1994) compared dynamic methods for the determination of modulus of elasticity with direct static methods for different types of French rocks. They used the mechanical resonance frequency and ultrasonic velocity techniques and concluded that these non-destructive methods are suitable for the determination of static modulus of elasticity. Kahraman (2001) presented correlation between uniaxial compressive strength values and the corresponding results of point load, Schmidt hammer, sound velocity and impact strength tests. He presented a non-linear relationship between sound velocity and uniaxial compressive strength with a coefficient of correlation of 0.83 . However he advised that the prediction is more 
reliable at low strength than at higher strength because the points are more dispersed at higher values. Begonha (1997) and Begonha et al. (2002) studied the mineralogical, chemical and geotechnical features of the granitic residual soils of the Oporto granite, the physical properties of the granitic rock, as well as the weathering effect in the geotechnical and physical properties. Those authors showed that all the properties of the Oporto granite are strongly affected by the weathering process. Arel and Tuğrul (2001) studied the weathering and its relation to geomechanical properties of granitic rocks from Turkey. They present several correlations between point load index, uniaxial compressive strength, slake durability, porosity, loss on ignition, dry and saturated unit weight and water properties. Tuğrul (2004) studied the changes in pore characteristics of different types of rock from Turkey due to weathering and presented relationships between both total and effective porosity and other engineering properties. Sharma and Singh (2007) presented a table with many relationships between P-wave velocity and uniaxial compressive strength reported by several researchers with coefficients of correlation ( $\mathrm{r}$ ) between 0.531 and 0.880. They also presented their own empirical relation for seven types of rocks with a coefficient of correlation of 0.9022. They concluded that $\mathrm{P}$-wave velocity is a reliable method for estimating not only $\sigma_{\mathrm{c}}$ but also impact strength index and slake durability index. Kiliç and Teymen (2008) used non-destructive and indirect methods to estimate the mechanical properties of rocks by statistical equations. They tested nineteen different rock types and pointed out satisfactory correlations between shore hardness, point load index, sound velocity, Schmidt hardness and porosity and uniaxial compressive strength, indirect tensile strength and abrasion resistance. They presented non-linear correlations between $\sigma_{c}$ and $\mathrm{V}_{\mathrm{p}}\left(\mathrm{R}^{2}=0.94\right)$ and uniaxial compressive strength and the porosity $\left(\mathrm{R}^{2}=0.93\right)$. However, the authors advertised that equations may not be suitable for rocks with very low porosity $(<2 \%)$.

The use of correlations like those mentioned above, should many times lead to unsatisfactory forecasts. To overcome this problem, artificial intelligent tools such as Data Mining techniques can be useful to build more accurate predictive models. The Data Mining is a step in the overall process of discovering useful knowledge from databases and consists in the application of suitable algorithms or techniques to extract knowledge from data and obtain a pattern or model. Neural networks and support vector machines are examples of DM algorithms. The ANN technique is the most widely used technique in the rock engineering domain. It has been used to build models to identify probable failure on rock masses (Guo et al., 2003), for rock classification (Millar and Hudson, 1994), for prediction of uniaxial compressive strength (Singh et al., 2001; Zorlu et al., 2008; Dehghan et al., 2010), tensile strength (Singh et al., 2001), modulus of elasticity of rocks (Majdi and Beiki, 2010; Dehghan et al., 2010; Miranda et al., 2011), the weathering degrees of rocks (Gokceoglu et al., 2009; Dagdelenler et al., 2011), etc. This technique is based on the functioning of the human nervous system and can handle data with complex relationships that can be strongly non linear. Support vector machines are alternative techniques to the ANN but scarce applied in rock engineering. Like the ANN, the SVM has a high degree of complexity. These DM techniques and the traditional multiple regression were used in this study to build models to forecast the $\sigma_{\mathrm{c}}$ and $\mathrm{E}$ of granitic rocks from Oporto, Portugal. As far as we know, SVM has not yet been applied to predict both $\sigma_{\mathrm{c}}$ and $\mathrm{E}$ of granitic or other rocks.

\section{Materials and methods}

\subsection{Petrographic characterization}

The studied rock, named the Oporto granite, is a light grey, two-mica, medium-grained, hypidiomorphic granite and is located in Oporto and surrounding areas. It is composed by quartz, microcline ( $\mathrm{k}$-feldspar), plagioclase muscovite and biotite. Muscovite is the dominant mica and microcline is frequently perthitic. Apatite, zircon and rutile are the accessory minerals. The fresh rock was submitted to a late post-magmatic alteration, being characterized by several generations of dioctahedral micas, chlorite, rare chlorite-smectite mixed-layer minerals and a pure smectite phase (Begonha, 1997; Begonha et al., 2002).

Climatic conditions of NW Portugal favour the granite weathering and its outcrops often display different degrees of weathering. Total weathering profile depths frequently exceed 20 to $30 \mathrm{~m}$ and granitic saprolites can be more than $10 \mathrm{~m}$ thick.

Clay minerals and associated minerals that characterize the bulk weathered rock and granitic saprolites are kaolinite, gibbsite, and chlorite-vermiculite mixed-layer (Begonha, 1997; Begonha et al., 2002). According to these authors the amount of plagioclase is significantly reduced at the very beginning of the weathering process (weathered rock). On the contrary, the relative increase of the microcline at the earlier stages of the weathering process and the decrease in later ones, indicate its higher resistance to weathering compared to plagioclase.

\subsection{Granite weathering effects in physical properties}

In this paper some of the more significant works on the Oporto granite (Begonha, 1997; Begonha et al., 2002) will be reviewed, from the particular context of the weathering effect in the physical properties of the granite.

The granite weathering was studied in order to obtain a physical property to be used as an index of the degree of weathering and to estimate other properties. Several tests were performed in order to obtain total porosity $\left(\mathrm{N}_{\mathrm{T}}\right)$, free 
porosity $\left(\mathrm{N}_{48}\right)$, dry bulk density (d), ultrasonic velocity $(\mathrm{v})$, uniaxial compressive strength $\left(\sigma_{\mathrm{c}}\right)$, modulus of elasticity (E) and strain in rupture $(\varepsilon)$. Table 1 presents the results published by Begonha (1997) that were used in this study and Table 2 shows the statistical assessments of the parameters of the Table 1.

The ISRM (1978) classification was used and rocks were classified as fresh (W1) to moderately-highly weathered (W3-W4) (Table 1). As it can be seen, most of the rocks are moderately weathered with less than half of the rock decomposed (W3).

Table 2 shows that the free porosity $\left(\mathrm{N}_{48}\right)$ presents the higher coefficient of variation and the dry bulk density (d) the lower. Therefore, $\mathrm{N}_{48}$ presents the greater variability and $d$ the lower variability. The other parameters present similar variability.

Among several non linear relationships between two physical parameters carried out by Begonha (1997) only $\sigma_{c}$ and $\mathrm{E}$ (engineering properties) will be treated in this study (Table 3). This study aimed to build more accurate models based on powerful techniques to forecast $\sigma_{\mathrm{c}}$ and $\mathrm{E}$ from other physical properties. To achieve this goal, DM techniques such as ANN, SVM and MR were used.

Figures 1 and 2 show the histograms of the uniaxial compressive strength and of the modulus of elasticity, respectively. It can be seen that most of the data have values of $\sigma_{c}$ between 60 and $120 \mathrm{MPa}$ and values of $\mathrm{E}$ between 6 and $12 \mathrm{GPa}$.

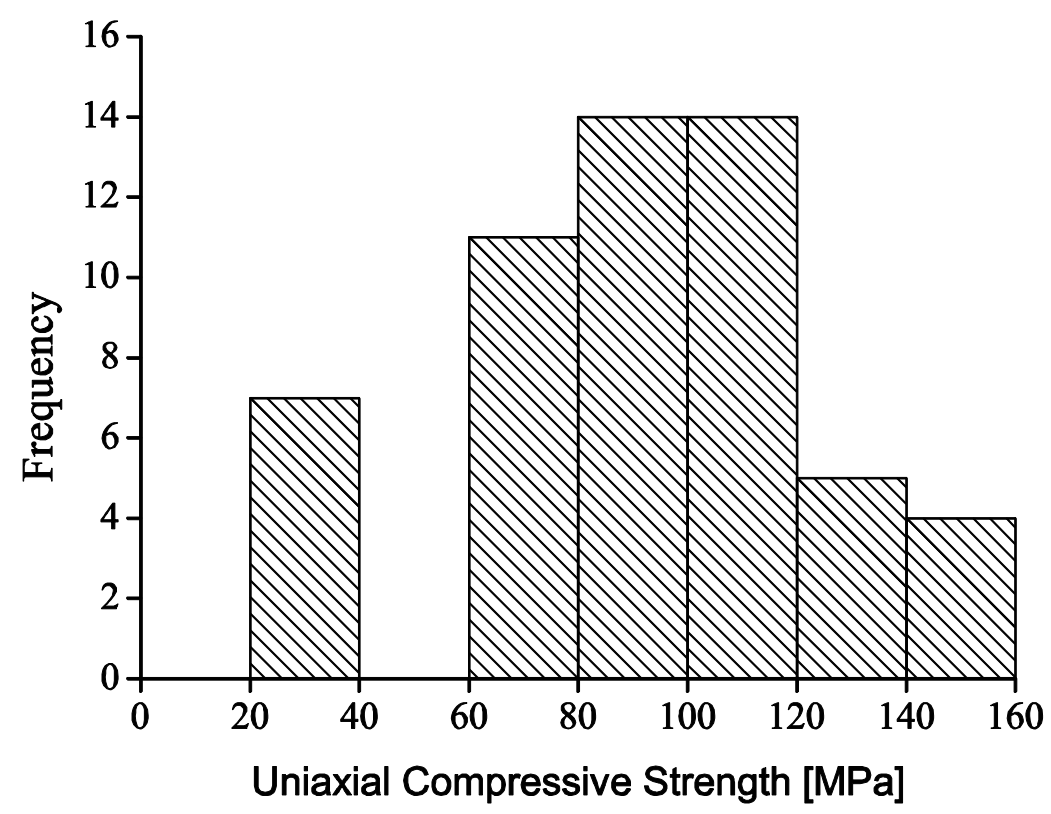

Fig. 1. Histogram of the uniaxial compressive strength.

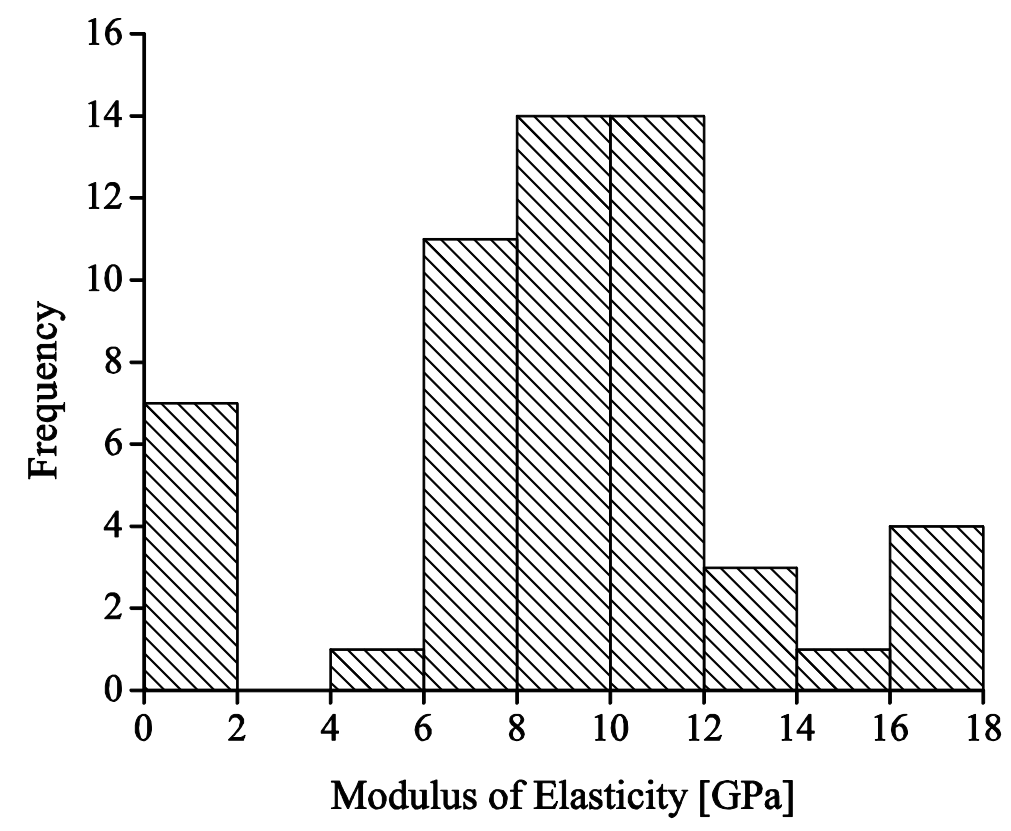

Fig. 2. Histogram of the modulus of elasticity. 


\subsection{Data Mining}

In this study the data mining process was applied to predict the uniaxial compressive strength and the modulus of elasticity. Artificial neural networks, support vector machines and multiple regressions were applied. It was used the environment R (R Development Core Team, 2010) with the RMiner library developed by Cortez (2010) and some available packages. The library RMiner presents a set of functions that make easier the use of DM algorithms both in classification and regression tasks. Both tasks require a supervised learning where there is a model fitting to a dataset of examples each composed by input variables and one output variable. The problems studied here are regression problems.

The ANN technique is based on the architecture of the human brain. The way the artificial neurons are linked each other defines the adopted architecture. The neurons communicate each other sending signals through the links. Each liaison has an associated weight, $\mathrm{w}_{\mathrm{i}, \mathrm{j}}$ ( $\mathrm{i}$ and $\mathrm{j}$ are neurons or nodes), and each neuron has an activation function that introduces a non-linear component. This study used a logistic activation function $\mathrm{f}$ given by $1 /\left(1+\mathrm{e}^{-\mathrm{x}}\right)$ and the following general equation:

$$
\hat{y}=w_{o, 0}+\sum_{j=I+1}^{o-1} f\left(\sum_{i=1}^{I} x_{i} w_{j, i}+w_{j, 0}\right) w_{o, i}
$$

where $\mathrm{x}_{\mathrm{i}}$ are the input parameters or nodes, $\mathrm{I}$ is the number of input parameters and $\mathrm{o}$ is the output parameter.

The multilayer perceptron (feed forward network) architecture (Haykin, 1999) with one hidden layer of HN hidden nodes was adopted in this research (Fig. 3). The grid search of the number of hidden nodes HN was $\{0,2,4,6,8,10,12,14,16,18,20\}$.

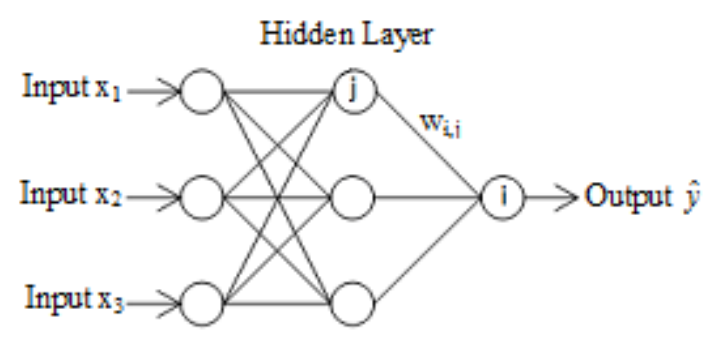

Fig. 3. Example of a multilayer perceptron.

The SVM technique was initially developed to classification problems by Cortes and Vapnik (1995). This method uses a non linear mapping to transform the input data into a multidimensional feature space (Fig. 4).

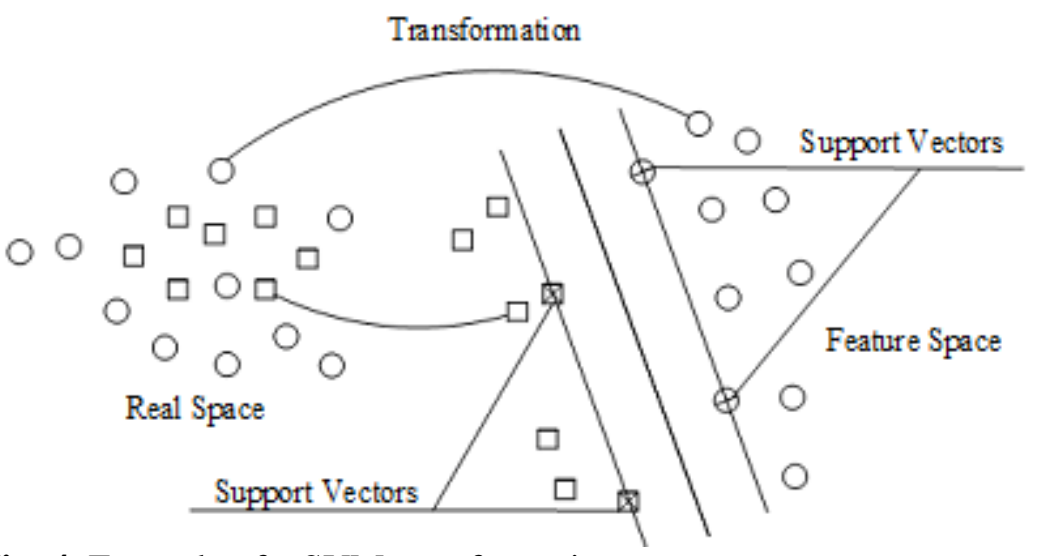

Fig. 4. Example of a SVM transformation.

After this transformation the SVM finds the best hyperplane inside the feature space. The non linear mapping depends on a kernel function $\mathrm{k}\left(\mathrm{x}, \mathrm{x}^{\prime}\right)$. This work uses the following kernel function:

$$
k\left(x, x^{\prime}\right)=e^{\left(-\gamma \cdot\left\|x-x^{\prime}\right\|^{2}\right)}, \quad \gamma>0
$$


The performance of the regression is affected by the kernel parameter, $\gamma$, a penalty parameter, $\mathrm{C}$, and the width of the $\varepsilon$-insensitive zone. To limit the searching space, $\mathrm{C}$ was considered equal 3 and it was used a heuristic for $\varepsilon$ (Cortez, 2010). Therefore, the search space was limited to the input values of $\gamma$ which in this study were $\left\{2^{-15}, 2^{-}\right.$ $\left.{ }^{13}, 2^{-11}, 2^{-9}, 2^{-7}, 2^{-6}, 2^{-5}, 2^{-4}, 2^{-3}, 2^{-2}, 2^{-1}, 2^{0}, 2^{1}, 2^{2}, 2^{3}\right\}$.

To test the predictive capacity of the data mining techniques the dataset was divided in two subsets. One, composed by 45 registers, was used to train the model, and other, composed by the remaining 10 registers, to test the model. With the training set it was used a 5-fold cross validation where the data was divided in five subsets of equal size. Four subsets were used to adjust the model whereas the remaining subset was used to test the model. This process was repeated until all the subsets have been tested. Ten runs of this process were carried on this study.

The model with the best performance in the training process was fitted with all the training dataset and was tested using the testing dataset composed by 10 register not used in the training process.

The performance of the models was assessed using the coefficient of determination $\mathrm{R}^{2}$ and the root mean square error RMSE (Equation 3).

$$
R M S E=\sqrt{\frac{1}{N} \sum_{i=1}^{N}\left(y_{i}-\hat{y}_{i}\right)^{2}}
$$

Where $\mathrm{y}_{\mathrm{i}}$ is the measured value, $\hat{\mathrm{y}}_{\mathrm{i}}$ is the predicted value and $\mathrm{N}$ is the number of samples.

The higher the $\mathrm{R}^{2}$ the better is the performance of the model. $\mathrm{R}^{2}$ equal 1 corresponds to an excellent performance. In relation to RMSE, the performance of the model increases as its value decreases.

\section{Results and Discussion}

\subsection{Uniaxial compressive strength}

The data mining models were tested using a single input variable and combinations of two or three variables $\left(\mathrm{N}_{48}, \mathrm{~d}\right.$ and $v$ ). The mean values of the root mean square error (RMSE) and the coefficient of determination $\left(\mathrm{R}^{2}\right)$ obtained during the training process are presented in Tables 4 and 5. According to Johnson (1984), correlation coefficient values (R) higher than \pm 0.8 are considered statistically significant at $95 \%$ confidence. This corresponds to $\mathrm{R}^{2}$ equal 0.64 . It can be seen that all the values presented in Table 5 are greater than 0.64 , which confirms the good predictive capacity of the models.

From the analysis of Tables 4 and 5 it can be seen that the best results for most of the combinations of input parameters were obtained with the SVM technique. When $d$ is used alone the MR model gave better results than the other models. The MR and SVM models had similar behaviour when all the input parameters are used. In relation to v\&d the SVM and MR had similar coefficient of determination but the SVM model had rather lower RMSE.

Among all the combinations and models, the best performance was obtained with the SVM model using $\mathrm{N}_{48}$ and $\mathrm{v}$ as input variables. This model was fitted with all the training set and the result is graphically presented in Fig. 5 which also presents the values obtained with the testing set. Table 6 presents both RMSE and $\mathrm{R}^{2}$ obtained in the correlations presented by Begonha (1997) (Table 3) and with the built SVM models using only one input parameter and the best combination $\left(\mathrm{N}_{48} \& \mathrm{v}\right)$ with all the training set. It can be seen that using all the training set all the SVM models gave better results than the equations presented by Begonha (1997) and Begonha et al. (2002). 


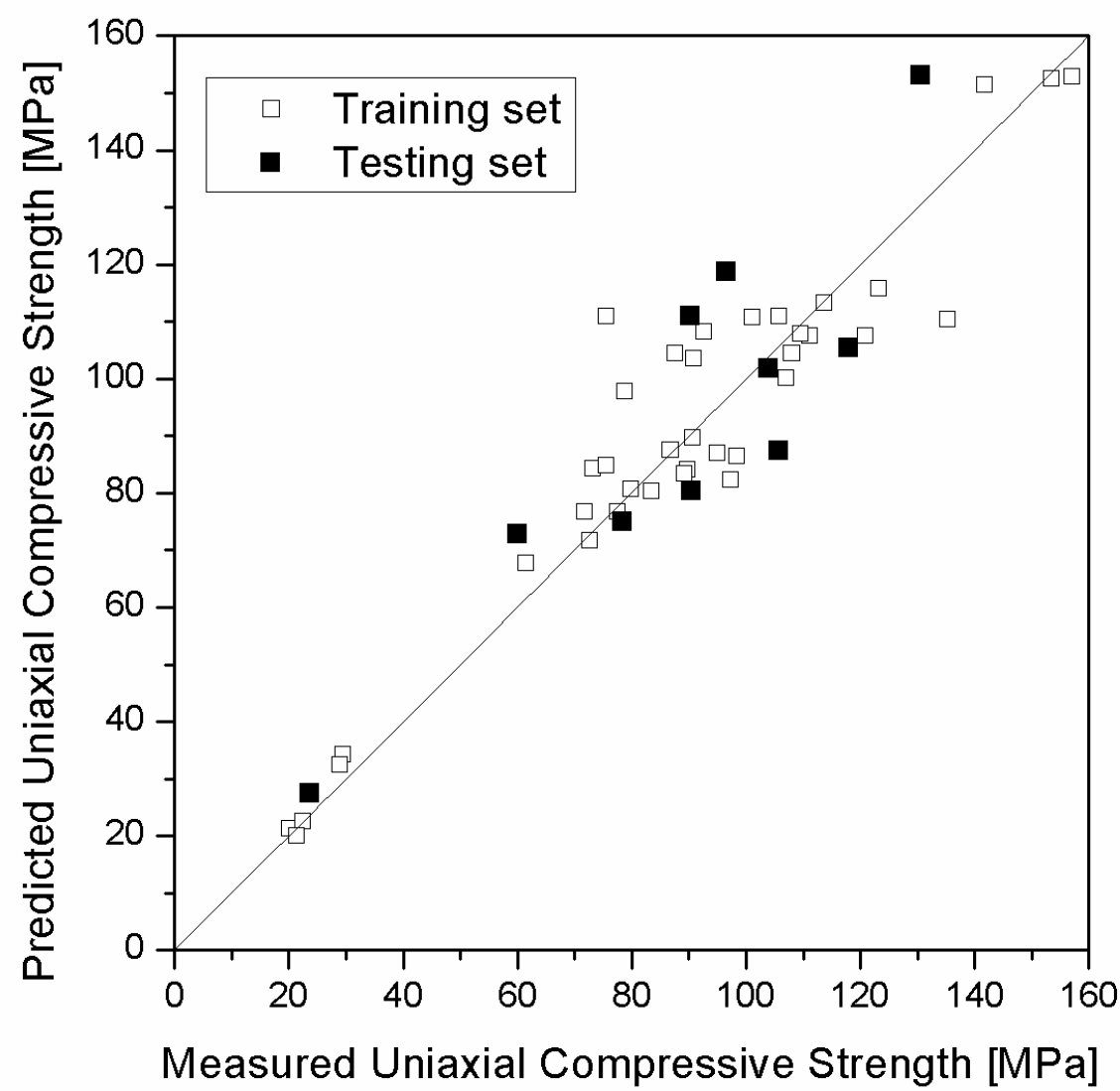

Fig. 5. Performance of the SVM model using the combination $\mathrm{N}_{48}$ and $\mathrm{v}$ in the prediction of $\sigma_{\mathrm{c}}$.

The results presented in Table 7, obtained with the testing set confirm the best performance of the SVM model with the combination $\mathrm{N}_{48}$ and $\mathrm{v}$. When the input parameter is $\mathrm{v}$ the equation presented by Begonha (1997) and Begonha et al. (2002) gave better results.

It must be stressed that the testing set is unknown for the DM models and all the dataset was used to obtain the equations presented by Begonha (1997) and Begonha et al. (2002).

\subsection{Modulus of Elasticity}

In relation to the modulus of elasticity similar analyses to those applied in relation to uniaxial compressive strength were performed. The results are presented in Tables 8 to 11 .

From the analysis of Tables 8 and 9 it can be seen that the best results for most of the combinations of input parameters were obtained with the SVM technique. Only for the combination $\mathrm{N}_{48} \& d$ the ANN model gave better results.

Among all the combinations and models, the best performance was obtained with the SVM model using $\mathrm{N}_{48}$ and $\mathrm{v}$ as input variables. This model was fitted with all the training set and the result is graphically presented in Fig. 6 which also presents the values obtained with the testing set. Table 10 presents both RMSE and $\mathrm{R}^{2}$ obtained in the correlations presented by Begonha (1997) (Table 3) and with the built SVM models using all the training set. It can be seen that using all the training set all the SVM models gave better results than the equations presented by Begonha (1997) and Begonha et al. (2002). 


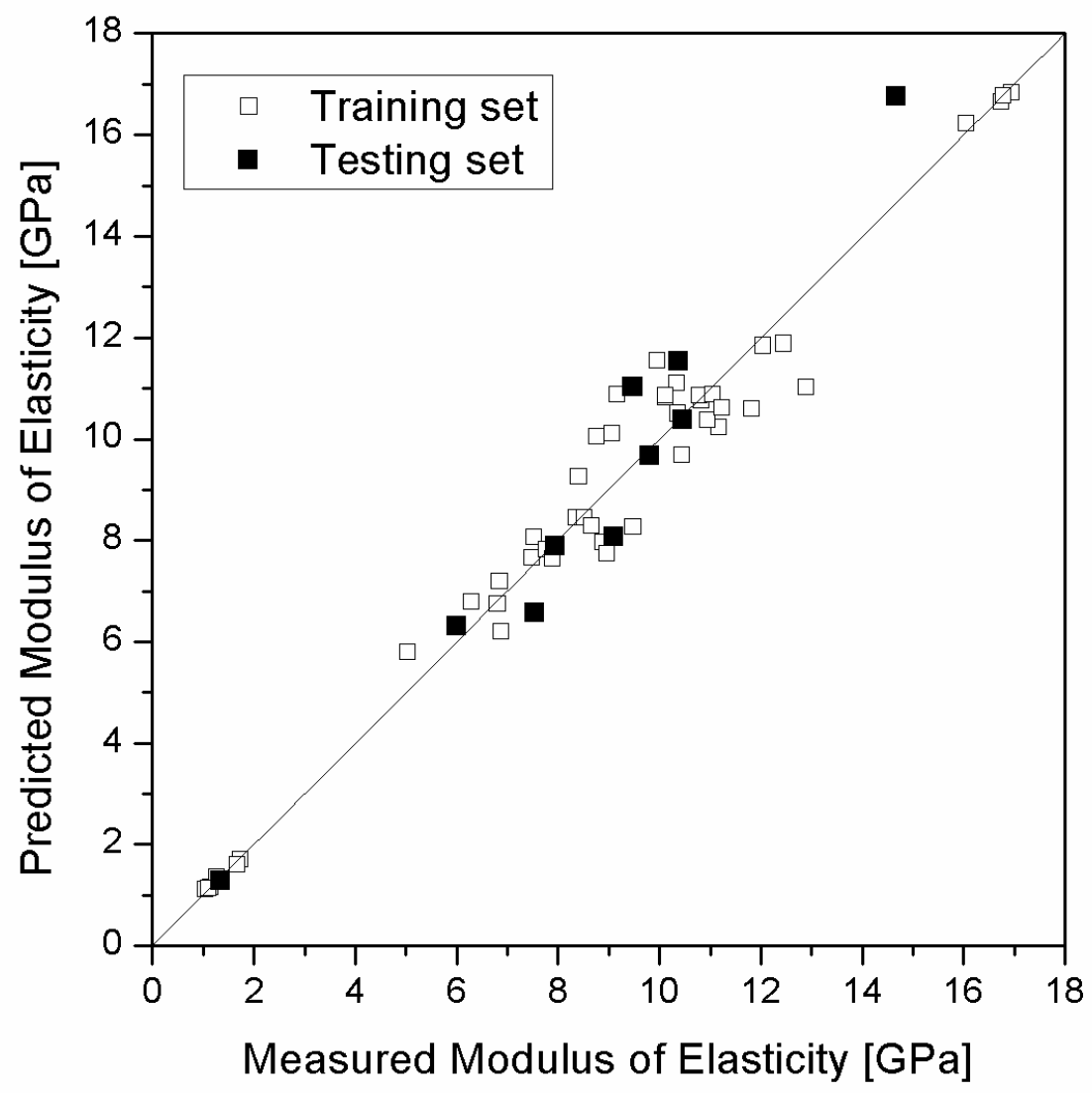

Fig. 6. Performance of the SVM model using the combination $\mathrm{N}_{48}$ and $\mathrm{v}$ in the prediction of $\mathrm{E}$.

The results presented in Table 11, obtained with the testing set confirm the best performance of the SVM model with the combination $\mathrm{N}_{48}$ and $\mathrm{v}$ and that all the SVM models have a better predictive capacity than the equations provided by Begonha (1997) and Begonha et al. (2002).

\section{Conclusions}

Free porosity $\left(\mathrm{N}_{48}\right)$, dry bulk density (d) and ultrasonic velocity (v) were used as input variables in multiple regression analysis, artificial neural networks and support vector machines in order to predict the uniaxial compressive strength $\left(\sigma_{\mathrm{c}}\right)$ and the modulus of elasticity (E) of granitic rocks. These DM techniques were used to improve the predictive capacity of $\mathrm{E}$ and $\sigma_{\mathrm{c}}$ in relation to the equations presented by Begonha (1997) and Begonha et al. (2002) that include only one input variable each time.

It was concluded that in general, when the SVM models were used, the results were better than those obtained with the Begonha's equations and the other models. The best results were obtained using $\mathrm{N}_{48}$ and $\mathrm{v}$ as input variables with the SVM model.

Both ANN and SVM models have the ability to capture the non linear features. However, the advantage of the SVM model over the ANN model is the absence of local minimum in the learning phase. Perhaps this advantage had led to its superiority over the ANN model.

It must be emphasize that Begonha's equations have been built with all the dataset whereas the results obtained with the DM techniques only used part of the dataset. This stress the quality of the results obtained with the DM techniques. Nevertheless, it must be emphasize that the DM techniques demand a great amount of data to extract knowledge. In this study only 45 registers were used in the training phase and 10 registers in the testing phase. Therefore, in spite of the good predictive capacity presented by the DM models, it is necessary to perform more tests to increase the dataset and perform more analyses to have a more consistent conclusion about the best model to apply. 


\section{Acknowledgements}

This study has been carried out under the framework of the strategic plan (2011-2012) of Territory, Environment and Construction Centre (C-TAC/UM), PEst-OE/ECI/UI4047/2011 and also of the Centre of Geological Research, Management and Valorisation of Resources (CIG-R), PEst-OE/CTE/UI0697/2011, approved by the Portuguese Foundation for Science and Technology (FCT). 


\section{References}

Arel, E., \& Tuğrul, A. (2001). Weathering and its relation to geomechanical properties of Cavusbasi granitic rocks in northwestern Turkey. Bulletin of Engineering Geology and the Environment, 60(2), 123-133.

Begonha, A. (1997). Meteorização do granito e deterioração da pedra em monumentos e edifícios da cidade do Porto. PhD Thesis, Universidade do Minho, Braga, Portugal.

Begonha, A., \& Sequeira Braga, M. A. (2002). Weathering of the Oporto granite: geotechnical and physical properties. Catena, 49, 57-76.

Christaras, B., Auger, F., \& Mosse, E. (1994). Determination of the moduli of elasticity of rocks. Comparison of the ultrasonic velocity and mechanical resonance frequency methods with direct static methods. Material and Structures, 27(4), $222-228$.

Cortes, C., \& Vapnik, V. (1995). Support Vector Networks. Machine Learning, 20(3): 273-297. Kluwer Academic Publishers. Cortez, P. (2010). Data Mining with Neural Networks and Support Vector Machines using the R/rminer Tool, In: P. Perner (Ed.), Advances in Data Mining. Proceedings of 10th Industrial Conference on Data Mining, lecture notes in artificial intelligence 6171 (pp. 572-583). Berlin: Springer.

Dagdelenler, G., Sezer, E. A., \& Gokceoglu, C. (2011). Some non-linear models to predict the weathering degrees of a granitic rock from physical and mechanical parameters. Expert Systems with Applications, 38, 7476-7485.

Dehghan, S., Sattari, Gh, Chehreh Chelgani, S., \& Aliabadi, M. A. (2010). Prediction of uniaxial compressive strength and modulus of elasticity for travertine samples using regression and artificial neural networks. Mining Science and Technology, 20, 41-46.

Gokceoglu, C., Zorlu, K., Ceryan, S., \& Nefeslioglu, H. A. (2009). A comparative study on indirect determination of degree of weathering of granites from some physical and strength parameters by two soft computing techniques, Materials Characterisation, 60, 1317-1327.

Guo, L., Wu, A., Zhou, K., \& Yao, Z. (2003). Pattern recognition and its intelligent realization of probable rock mass failure based on RES approach. Chinese Journal of Nonferrous Metals. 13(3): 749-753.

Haykin, S. (1999). Neural Networks - A Compreensive Foundation. (2nd ed). New Jersey: Prentice-Hall.

Irfan, T. Y., \& Dearman, W. R. (1978). The engineering petrography of weathered granite in Cornwall, England. Quarterly Journal of Engineering Geology, 11, 233-244.

ISRM (1978). International society of rock mechanics 1978. Methods for the quantitative description of rock masses and descontinuities. Int. Journal of Rock Mechanics and Mining Sciences \& Geomechanics Abstracts, 15, 319-368.

Johnson, R. (1984). Elementary statistics. Duxbury Press, Boston, 86-106.

Kahraman, S. (2001). Evaluation of simple methods for assessing the uniaxial compressive strength of rock. Int. Journal of Rock Mechanics and Mining Sciences, 38, 981-994.

Kiliç, A., \& Teymen, A. (2008). Determination of mechanical properties of rocks using simple methods, Bulletin of Engineering Geology and the Environment, 67 (2): 237-244.

Majdi, A., \& Beiki, M. (2010). Evolving neural networks using a genetic algorithm for predicting the deformation modulus of rock masses, International Journal of Rock Mechanics and Mining Sciences, 47, 246-253.

Millar, D. L., \& Hudson, J. A. (1994). Performance Monitoring of Rock Engineering Systems using Neural Networks. Transactions of the Institution of Mining and Metallurgy Section A - Mining Industry, 103, A3-A16.

Miranda, T., Gomes Correia, A., Santos, M., Ribeiro e Sousa, L., \& Cortez, P. (2011). New models for strength and deformability parameter calculation in rock masses using data-mining techniques, International Journal of Geomechanics, 11 (1), 44-58.

R Development Core Team (2010) R: A language and environment for statistical computing. R Foundation for Statistical Computing, Vienna, Austria. http://www.R-project.org, ISBN 3-900051-12-7.

Sharma, P.K., \& Singh, T. N. (2007). A correlation between P-wave velocity, impact strength index, slake durability index and uniaxial compressive strength. Bulletin of Engineering Geology and the Environment. 67(1), 17-22.

Singh, V. K., Singh, D. \& Singh, T. N. (2001). Prediction of strength properties of some schistose rocks from petrographic properties using artificial neural networks, International Journal of Rock Mechanics and Mining Sciences, 38, $269-284$.

Tiryaki, B. (2008). Predicting intact rock strength for mechanical excavation using multivariate statistical, artificial neural networks, and regression trees. Engineering Geology, 99, 51-60.

Tuğrul, A. (2004). The effect of weathering on pore geometry and compressive strength of selected rock types from Turkey. Engineering Geology, 75, 215-227.

Zorlu, K., Gokceoglu, C., Ocakoglu, F., Nefeslioglu, H. A. \& Acikalin, S. (2008). Prediction of uniaxial compressive strength of sandstones using petrography-based models. Engineering Geology, 96, 141-158. 
Table 1

Experimental results of tests for determining E and $\sigma_{\mathrm{c}}$ (Begonha, 1997).

\begin{tabular}{|c|c|c|c|c|c|c|}
\hline No. & $\mathrm{N}_{48}(\%)$ & $\mathrm{D}$ & $\mathrm{V}(\mathrm{m} / \mathrm{s})$ & $\sigma_{\mathrm{c}}(\mathrm{MPa})$ & $\mathrm{E}(\mathrm{GPa})$ & Weathering \\
\hline 1 & 2.75 & 2.57 & 2960 & 78.8 & 8.41 & W3 \\
\hline 2 & 2.45 & 2.58 & 3030 & 103.9 & 9.81 & W3 \\
\hline 3 & 2.59 & 2.57 & 3320 & 87.6 & 8.77 & W3 \\
\hline 4 & 3.1 & 2.56 & 2090 & 97.3 & 9.48 & W3 \\
\hline 5 & 3 & 2.57 & 2360 & 95 & 8.37 & W3 \\
\hline 6 & 2.98 & 2.55 & 2310 & 98.4 & 8.51 & W3 \\
\hline 7 & 4.33 & 2.52 & 2550 & 77.5 & 6.3 & W3 \\
\hline 8 & 3.6 & 2.54 & 2800 & 105.7 & 9.11 & W3 \\
\hline 9 & 3.68 & 2.55 & 2870 & 86.8 & 7.53 & W3 \\
\hline 10 & 4.18 & 2.52 & 2730 & 79.8 & 6.85 & W3 \\
\hline 11 & 9.11 & 2.37 & 1400 & 20.2 & 1.04 & W3-W4 \\
\hline 12 & 8.46 & 2.39 & 1540 & 23.7 & 1.35 & W3-W4 \\
\hline 13 & 8.92 & 2.37 & 1390 & 22.4 & 1.15 & W3-W4 \\
\hline 14 & 8.34 & 2.4 & 1500 & 23.3 & 1.28 & W3-W4 \\
\hline 15 & 9.2 & 2.37 & 1340 & 21.3 & 1.1 & W3-W4 \\
\hline 16 & 7.79 & 2.41 & 1690 & 29.4 & 1.74 & W3-W4 \\
\hline 17 & 7.93 & 2.41 & 1640 & 29 & 1.68 & W3-W4 \\
\hline 18 & 4.6 & 2.5 & 2460 & 60 & 6.01 & W3 \\
\hline 19 & 4.85 & 2.5 & 2260 & 61.5 & 5.03 & W3 \\
\hline 20 & 4.38 & 2.51 & 2590 & 71.8 & 6.81 & W3 \\
\hline 21 & 3.89 & 2.53 & 2780 & 73.2 & 7.49 & W3 \\
\hline 22 & 4.47 & 2.51 & 2520 & 78.5 & 7.55 & W3 \\
\hline 23 & 4.64 & 2.49 & 2400 & 72.7 & 6.88 & W3 \\
\hline 24 & 2.99 & 2.56 & 3570 & 108 & 11.16 & W3 \\
\hline 25 & 2.89 & 2.55 & 3760 & 92.6 & 10.11 & W3 \\
\hline 26 & 2.94 & 2.56 & 3750 & 111.2 & 10.83 & W3 \\
\hline 27 & 2.95 & 2.56 & 3610 & 118.1 & 10.46 & W3 \\
\hline 28 & 3.27 & 2.54 & 3460 & 107 & 10.45 & W3 \\
\hline 29 & 3.01 & 2.56 & 3530 & 90.9 & 9.07 & W3 \\
\hline 30 & 3.69 & 2.54 & 2680 & 75.6 & 7.77 & W3 \\
\hline 31 & 3.61 & 2.55 & 2310 & 83.5 & 7.9 & W3 \\
\hline 32 & 3.43 & 2.55 & 2450 & 89.7 & 8.88 & W3 \\
\hline 33 & 3.65 & 2.55 & 2550 & 89.3 & 8.96 & W3 \\
\hline 34 & 3.4 & 2.55 & 2160 & 90.4 & 7.96 & W3 \\
\hline 35 & 2.41 & 2.58 & 3980 & 123.2 & 12.05 & W3 \\
\hline 36 & 2.72 & 2.56 & 3610 & 120.9 & 11.81 & W3 \\
\hline 37 & 2.64 & 2.57 & 3750 & 135.2 & 12.89 & W3 \\
\hline 38 & 3.78 & 2.53 & 3080 & 90.7 & 8.66 & W3 \\
\hline 39 & 2.36 & 2.59 & 3600 & 101 & 10.79 & W3 \\
\hline 40 & 2.32 & 2.58 & 3590 & 75.6 & 9.17 & W3 \\
\hline 41 & 2.49 & 2.59 & 3700 & 90.3 & 9.48 & W3 \\
\hline 42 & 2.12 & 2.58 & 3620 & 113.6 & 10.35 & W3 \\
\hline 43 & 2.32 & 2.58 & 3370 & 109.5 & 10.95 & W3 \\
\hline 44 & 2.32 & 2.59 & 3590 & 105.8 & 11.05 & W3 \\
\hline 45 & 0.61 & 2.62 & 5740 & 157 & 16.94 & W1 \\
\hline 46 & 0.61 & 2.64 & 5610 & 141.7 & 16.73 & $\mathrm{~W} 1$ \\
\hline 47 & 0.61 & 2.63 & 5700 & 153.5 & 16.77 & $\mathrm{~W} 1$ \\
\hline 48 & 0.52 & 2.65 & 5690 & 130.6 & 14.67 & W1 \\
\hline 49 & 0.63 & 2.63 & 5370 & 153 & 16.05 & W1 \\
\hline 50 & 2.24 & 2.58 & 3400 & 103.5 & 10.37 & W3 \\
\hline 51 & 2.19 & 2.59 & 3540 & 104 & 10.12 & W3 \\
\hline 52 & 2.21 & 2.59 & 3440 & 110.3 & 11.24 & W3 \\
\hline 53 & 1.6 & 2.61 & 3670 & 96.6 & 10.38 & W2 \\
\hline 54 & 1.62 & 2.61 & 3680 & 100.3 & 9.96 & W2 \\
\hline 55 & 1.6 & 2.61 & 3810 & 132.7 & 12.45 & W2 \\
\hline
\end{tabular}


Table 2

Basic descriptive statistics of the rock properties used in database.

\begin{tabular}{cccccc}
\hline Symbol & Minimum & Mean & $\begin{array}{c}\text { Maximu } \\
\mathrm{m}\end{array}$ & $\begin{array}{c}\text { Standard } \\
\text { Deviation }\end{array}$ & $\begin{array}{c}\text { Coefficient of } \\
\text { variation }\end{array}$ \\
\hline $\mathrm{N}_{48}(\%)$ & 0.52 & 3.55 & 9.20 & 2.20 & 61.94 \\
\hline $\mathrm{d}$ & 2.37 & 2.54 & 2.65 & 0.07 & 2.72 \\
\hline $\mathrm{v}(\mathrm{m} / \mathrm{s})$ & 1340 & 3125.46 & 5740 & 1084.82 & 34.71 \\
\hline$\sigma_{\mathrm{c}}(\mathrm{MPa})$ & 20.20 & 90.97 & 157.00 & 33.72 & 37.07 \\
\hline $\mathrm{E}(\mathrm{GPa})$ & 1.04 & 8.89 & 16.94 & 3.89 & 43.76 \\
\hline
\end{tabular}


Table 3

Correlations developed by Begonha (1997) related to engineering properties.

\begin{tabular}{cc}
\hline Correlations & $\mathrm{R}^{2}$ \\
\hline$\sigma_{c}=184.9028 \times 0.7952^{N 48}$ & 0.931 \\
\hline$\sigma_{c}=4.2830 \times 10^{-6} \times d^{17.9721}$ & 0.910 \\
\hline$\sigma_{c}=-594.7097+85.8524 \times \ln v$ & 0.835 \\
\hline$E=23.2826 \times 0.7262^{N 48}$ & 0.930 \\
\hline$E=4.5065 \times 10^{-10} \times d^{25.2266}$ & 0.933 \\
\hline$E=-78.9227+11.0114 \times \ln v$ & 0.880 \\
\hline$E=0.0183 \sigma^{1.3646}$ & 0.982
\end{tabular}


Table 4

Mean values of RMSE obtained in the cross-validation scheme for different combination of input parameters.

\begin{tabular}{cccccccc}
\hline & $\mathrm{M} 1$ & \multicolumn{7}{c}{$\mathrm{M} 2$} & $\mathrm{M} 3$ \\
\hline & $\mathrm{N}_{48}$ & $\mathrm{v}$ & $\mathrm{d}$ & $\mathrm{N}_{48} \& \mathrm{v}$ & $\mathrm{v} \& \mathrm{~d}$ & $\mathrm{~N}_{48} \& \mathrm{~d}$ & $\mathrm{~N}_{48} \& \mathrm{v} \& \mathrm{~d}$ \\
\hline ANN & 13.69 & 14.74 & 14.98 & 11.31 & 11.77 & 13.09 & 11.49 \\
\hline SVM & 12.52 & 14.17 & 14.73 & 10.75 & 11.53 & 13.01 & 11.12 \\
\hline MR & 13.13 & 16.11 & 14.19 & 10.87 & 12.27 & 13.05 & 11.09 \\
\hline
\end{tabular}


Table 5

Mean values of $\mathrm{R}^{2}$ obtained in the cross-validation scheme for different combination of input parameters.

\begin{tabular}{cccccccc}
\hline & $\mathrm{M} 1$ & \multicolumn{7}{c}{$\mathrm{M} 2$} & & $\mathrm{M} 3$ \\
\hline & $\mathrm{N}_{48}$ & $\mathrm{v}$ & $\mathrm{d}$ & $\mathrm{N}_{48} \& \mathrm{v}$ & $\mathrm{v} \& \mathrm{~d}$ & $\mathrm{~N}_{48} \& \mathrm{~d}$ & $\mathrm{~N}_{48} \& \mathrm{v} \& \mathrm{~d}$ \\
\hline ANN & 0.842 & 0.819 & 0.811 & 0.892 & 0.883 & 0.858 & 0.888 \\
\hline SVM & 0.868 & 0.831 & 0.819 & 0.904 & 0.887 & 0.859 & 0.896 \\
\hline MR & 0.854 & 0.781 & 0.830 & 0.900 & 0.892 & 0.858 & 0.896 \\
\hline
\end{tabular}


Table 6

RMSE and $\mathrm{R}^{2}$ values using all the training set.

Begonha

SVM

1997

\begin{tabular}{cccccccc}
\hline & $\mathrm{N}_{48}$ & $\mathrm{v}$ & $\mathrm{d}$ & $\mathrm{N}_{48} \& \mathrm{v}$ & $\mathrm{N}_{48}$ & $\mathrm{v}$ & $\mathrm{d}$ \\
\hline $\mathrm{RMSE}$ & 12.16 & 13.03 & 13.54 & 10.43 & 11.10 & 10.86 & 11.56 \\
\hline $\mathrm{R}^{2}$ & 0.881 & 0.857 & 0.850 & 0.910 & 0.896 & 0.903 & 0.887 \\
\hline
\end{tabular}


Table 7

RMSE and $\mathrm{R}^{2}$ values using all the testing set. Begonha

SVM

1997

\begin{tabular}{cccccccc}
\hline & $\mathrm{N}_{48}$ & $\mathrm{v}$ & $\mathrm{d}$ & $\mathrm{N}_{48} \& \mathrm{v}$ & $\mathrm{N}_{48}$ & $\mathrm{v}$ & $\mathrm{d}$ \\
\hline $\mathrm{RMSE}$ & 19.28 & 15.80 & 22.57 & 14.87 & 16.28 & 17.74 & 16.15 \\
\hline $\mathrm{R}^{2}$ & 0.713 & 0.727 & 0.676 & 0.792 & 0.763 & 0.700 & 0.716 \\
\hline
\end{tabular}


Table 8

Mean values of RMSE obtained in the cross-validation scheme for different combination of input parameters.

\begin{tabular}{cccccccc}
\hline & $\mathrm{M} 1$ & \multicolumn{7}{c}{$\mathrm{M} 2$} & $\mathrm{M} 3$ \\
\hline & $\mathrm{N}_{48}$ & $\mathrm{v}$ & $\mathrm{d}$ & $\mathrm{N}_{48} \& \mathrm{v}$ & $\mathrm{v} \& \mathrm{~d}$ & $\mathrm{~N}_{48} \& \mathrm{~d}$ & $\mathrm{~N}_{48} \& \mathrm{v} \& \mathrm{~d}$ \\
\hline ANN & 1.192 & 1.482 & 2.016 & 0.930 & 1.022 & 1.127 & 0.905 \\
\hline SVM & 1.138 & 1.307 & 1.425 & 0.850 & 0.920 & 1.209 & 0.894 \\
\hline MR & 1.457 & 1.442 & 1.574 & 0.908 & 0.931 & 1.451 & 0.941 \\
\hline
\end{tabular}


Table 9

Mean values of $\mathrm{R}^{2}$ obtained in the cross-validation scheme for different combination of input parameters.

\begin{tabular}{cccccccc}
\hline & $\mathrm{M} 1$ & \multicolumn{7}{c}{$\mathrm{M} 2$} & & $\mathrm{M} 3$ \\
\hline & $\mathrm{N}_{48}$ & $\mathrm{v}$ & $\mathrm{d}$ & $\mathrm{N}_{48} \& \mathrm{v}$ & $\mathrm{v} \& \mathrm{~d}$ & $\mathrm{~N}_{48} \& \mathrm{~d}$ & $\mathrm{~N}_{48} \& \mathrm{v} \& \mathrm{~d}$ \\
\hline ANN & 0.909 & 0.861 & 0.819 & 0.945 & 0.934 & 0.920 & 0.948 \\
\hline SVM & 0.918 & 0.891 & 0.874 & 0.954 & 0.947 & 0.908 & 0.949 \\
\hline MR & 0.866 & 0.868 & 0.843 & 0.948 & 0.945 & 0.867 & 0.944 \\
\hline
\end{tabular}


Table 10

RMSE and $\mathrm{R}^{2}$ values using all the training set

\begin{tabular}{cccccccc}
\hline & $\begin{array}{c}\text { Begonha } \\
(1997)\end{array}$ & & & & & & \\
\hline & $\mathrm{N}_{48}$ & $\mathrm{v}$ & $\mathrm{d}$ & $\mathrm{N}_{48} \& \mathrm{v}$ & $\mathrm{N}_{48}$ & $\mathrm{v}$ & $\mathrm{d}$ \\
\hline $\mathrm{RMSE}$ & 1.476 & 1.224 & 1.566 & 0.728 & 0.965 & 0.922 & 1.463 \\
\hline $\mathrm{R}^{2}$ & 0.900 & 0.907 & 0.871 & 0.966 & 0.941 & 0.946 & 0.880 \\
\hline
\end{tabular}


Table 11

RMSE and $\mathrm{R}^{2}$ values using all the testing set Begonha SVM (1997)

\begin{tabular}{cccccccc}
\hline & $\mathrm{N}_{48}$ & $\mathrm{v}$ & $\mathrm{d}$ & $\mathrm{N}_{48} \& \mathrm{v}$ & $\mathrm{N}_{48}$ & $\mathrm{v}$ & $\mathrm{d}$ \\
\hline $\mathrm{RMSE}$ & 2.222 & 1.274 & 2.865 & 1.012 & 1.265 & 1.245 & 1.094 \\
\hline $\mathrm{R}^{2}$ & 0.851 & 0.898 & 0.822 & 0.951 & 0.932 & 0.904 & 0.906 \\
\hline
\end{tabular}

